\title{
Musculoskeletal consequences in cyber-addicted students - Is it really a matter of health? A ROC curve analysis for prioritizing risk factors
}

\section{Rashid Heidari Moghadam}

Hamadan University of Medical Sciences School of Public Health

Mohammad Babamiri

Hamadan University of Medical Sciences School of Public Health

Fakhradin Ghasemi

Hamadan University of Medical Sciences School of Public Health

Mohammad Ebrahim Ghaffari

Guilan University of Medical Sciences

\section{Mahdi Razie}

Hamadan University of Medical Sciences School of Public Health

Khadijeh Bandehelahi

Hamadan University of Medical Sciences School of Public Health

Alireza Mortezapour ( $\nabla$ amortezapour258@gmail.com )

Hamadan University of Medical Sciences School of Public Health https://orcid.org/0000-0001-63562244

\section{Research article}

Keywords: Neck disorder, virtual environment, Addictive behavior, Internet addiction, Social media, online game

Posted Date: August 3rd, 2019

DOl: https://doi.org/10.21203/rs.2.12366/v1

License: (c) (i) This work is licensed under a Creative Commons Attribution 4.0 International License. Read Full License 


\section{Abstract}

Background The high prevalence and also multiple consequences of addiction to various online content, including online games and social networks, have become a major challenge. The ability to predict musculoskeletal disorders from this addiction can help reveal in students' health status in the near future. The aim of this study was to determine the prevalence of this addiction and the ability to predict neck pain from this matter in students. Methods This study was carried out among 665 students. Data collection was performed through three questionnaires on problematic use of online games, social networking addiction, and Nordic musculoskeletal disorders. Data were compared with Chi-square and independent T-test, and the logistic regression model was then presented at a significant level of 0.05 . Finally, the area under the receiver operating characteristic (ROC) curve and Discriminant analysis with SPSS and STATA software were conducted to clarify associations. Results The prevalence of Internetrelated content addiction was $32.8 \%$. The results showed that addiction to social networks and online games can increase the risk of neck disorder. Also 0.58 area under ROC curve depicted the ability to predict neck pain from this addiction. Conclusions In students with internet - related content addiction, neck disorder can be predicted. Given the high prevalence of internet addiction in students, it is essential to take immediate and appropriate interventions to avoid the associated adverse effects such as neck problems.

\section{Background}

Nowadays College students as a privileged population have been located in a spotlight of every societies[1]. Around one-half of US 18 to 24 years citizen are enrolled in universities [2]. Right now, more than four million students study at various universities in Iran[3]. Attending students in universities have many ways through which they might have a promotive effect on mental health[1]. While all of these situations offer chances for maturity and perfection, they also may result in onset or recurrence of various types of mental disorders[4]. Adolescents and youth are more susceptible to psychological abnormalities due to the rapid age-related changes[5]. Diminution of immunity to the suffering and impairment associated with mental illness is one of their attributes[1]. Students represent a substantial subject in which to access to mental health care[6]. Mental health problems are highly prevalent among university students and illustrate a growing concern[1]. The last decade has witnessed an enormous increase in the body of literature on the newly emerging mental health issues associated with Internet addiction in students[7]. Internet addiction is not yet a DSM IV diagnosis, but its definition is based on the DSM IV addictive behavior criteria[8]. Among university students, internet addiction prevalence has been estimated to be $0.8 \%$ in Italy[9], $2.8 \%$ in Iran[10], and $18.3 \%$ in Great Britain[11]. The high prevalence rate of internet addiction was found in a sample of Chinese students[12]. Various problematic use of the Internet has been reported among university students[11]. Gaming has been much investigated as an online application with an Incredibly high addictive output[13]. Moreover, the use of social networks is another one[14]. Universities have started to consider the Internet dependence issue and ways through which it might influence their students[15]. one of the beneficial ways to better understand Internet-related 
addicted behaviors is to study its consequences[16]. Problematic Internet use interrupts main function of the musculoskeletal system[17](17). Social network addiction and psychosomatic outcomes were subjects of a comprehensive systematic review[18]. Adverse Health Effects (neck and shoulder pain) were demonstrated to be a challenging issue among Medical Students who use Facebook addictively[19]. The relationship between online gaming addiction and Korean students' carpal tunnel syndrome was the subject of a recent study[20]. Zheng et al. showed that Overall prevalence of cervical pain in problematic internet user was $48 \%[17]$. One of the most remarkable health challenges in students is musculoskeletal disorders, especially in the neck[21]. A prospective cohort study showed that Neck pain is quite common among students[22]. Musculoskeletal disorders were most commonly declared by students at their neck[23]. In previous studies, there have been mentioned many reasons for neck disorder[24]. From all, psychosocial factors were significant predictors for such a problem [25, 26]. Less attention has been paid to the Internet-related addictive behaviors - a psychosocial issue - [27, 28], as a predictor of neck disorders, especially in students. So the aim of present study was to predict the neck disorder associated to internet-related content addiction and compare the importance of independent variables among university students.

\section{Methods}

This cross-sectional study was conducted at in 2018. The sample was randomly selected from the population of students of After receiving the goals and accepting the informed consent form, all participants in this study $(n=665)$ were entered into the study. All the scientific and executive stages of this study have been approved by the Ethics Committee (registry number: REC.1397.314). The completion of at least one year of university education was the main criterion for inclusion in this study. Students with previous history of neck injury or disorder (as a self - reported question), were excluded from the study. The following questionnaires were used for data collection. Demographic information was also collected.

\subsection{Virtual Social Network Addiction Questionnaire:}

This tool contains 43 questions that were rated as five-point Likert (never, almost never, sometimes, often and always). Seven dimensions of addiction to virtual social networking are measured in this questionnaire. These dimensions include loss of control, academic failure, dependency, avoidance syndrome, mood changes, reduced interest in other activities and social conflicts. The minimum and maximum attainable scores for each student were 43 and 215, respectively. To answer the main questions of the study, only the total score of the questionnaire, which represents the total score of social network addiction, was used. The validity and reliability of this questionnaire were approved in the Lindsay et al. study[29]. This tool also used in ......... students after the acquisition of an acceptable level of reliability and validity in the same culture study[30].

\subsection{Problematic online Game Questionnaire:}


Another tool to collect the required data was the problematic online game questionnaire[31]. The instrument has 18 questions to be answered by the participants in the five - point Likert (never, rarely, sometimes, often, and always). This tool has six sub-scales, including social isolation, interpersonal conflicts, excessive use, neglect, immersion and fascination. In order to measure addiction to online games, only the final scores achieved were used in the statistical analysis. The validity and reliability of this questionnaire have been confirmed by Kuss DJ et.al[32]. Aminimanesh et al. [33] have validated this instrument in accordance with Culture.

\subsection{Nordic musculoskeletal questionnaire:}

Data on neck musculoskeletal disorders were collected by Nordic questionnaire [34]. Participants answered questions on neck disorder in three periods, in general, in the past month and the day before. Their responses were based on a body diagram.

In this study, descriptive results were reported in terms of mean, percentage and standard deviation. Participants' data were compared using Chi-square, T-test and then simple and multiple logistic regression were presented. The surface under the receiver operating characteristic (ROC) curve was used to compare the importance of independent variables in prediction neck pain. Discriminant analysis was utilized to propose a function to classify people who were not involved in the analysis into one of the two groups - with and without neck pain-. The level of confidence in presenting results was 95 percent. The SPSS version 16 and STATA version 11 software packages were used for data analysis.

\section{Results}

Out of 665 subjects, 250 (37.6\%) were male and 415 (62.4\%) were female. Based on the level of education, Bachelor degree with 350 students (52.6\%) and associate degree with 60 students (9\%) were the highest and lowest number of participants in the study (Table1). The mean (standard deviation) of the students' age was 22.12(0.15) years (Table2). Prevalence of addiction to Internet-related contents (students who were simultaneously addicted to online games and social networks) was 32.8 percent among participants.

Table 1: The frequency of subjects by gender and level of education in the two study groups

\begin{tabular}{|c|c|c|c|c|c|}
\hline \multirow[t]{2}{*}{ p-value } & \multirow[t]{2}{*}{ Test statistic } & \multicolumn{2}{|c|}{ neck pain } & \multirow[t]{2}{*}{ Category } & \multirow[t]{2}{*}{ Variable } \\
\hline & & Yes (\%) & No (\%) & & \\
\hline \multirow[t]{2}{*}{0.026} & 4.98 & $153(61.2)$ & $97(38.8)$ & Male & Sex \\
\hline & & $289(69.6)$ & $126(30.4)$ & Female & \\
\hline \multirow[t]{4}{*}{0.089} & 6.53 & $32(53.3)$ & $28(46.7)$ & Associated degree & Education \\
\hline & & $241(68.9)$ & 109 (31.1) & Bachelor degree & \\
\hline & & $60(62.5)$ & $36(37.5)$ & MSc degree & \\
\hline & & $109(68.9)$ & $50(31.4)$ & $\mathrm{PhD}$ & \\
\hline
\end{tabular}


Table 2: Effect of independent variables on neck pain using logistic regression

\begin{tabular}{ccccc}
\hline & $\begin{array}{c}\text { Odd ratio, 95\% Cl } \\
\text { (Lower-Upper) }\end{array}$ & $\begin{array}{c}\text { p-value } \\
\text { Adjusted Odd ratio, 95\% Cl } \\
\text { (Lower-Upper) }\end{array}$ & p-value \\
\hline Associated degree & - & 0.093 & - & 0.239 \\
Bachelor degree & $1.93(1.11-3.37)$ & 0.020 & $1.57(0.88-2.78)$ & 0.123 \\
MSc degree & $1.46(0.76-2.80)$ & 0.258 & $1.37(0.69-2.72)$ & 0.360 \\
PhD & $1.91(1.04-3.50)$ & 0.037 & $1.89(1.01-3.55)$ & 0.047 \\
female & $1.45(1.05-2.02)$ & 0.026 & $1.83(1.28-2.62)$ & 0.001 \\
Age & $0.99(0.96-1.04)$ & 0.884 & $0.99(0.95-1.04)$ & 0.960 \\
addiction & $2.28(1.57-3.31)$ & $<0.001$ & $2.45(1.65-3.63)$ & $<0.001$ \\
\hline
\end{tabular}

The individual and simultaneous (adjusted) effects of each independent variable are shown in the abovementioned table. The unadjusted effect of the independent variables showed that the level of education, gender and Internet-related content addiction significantly affected the neck pain. The probability of developing neck pain in bachelor and Ph.D. students was 1.57 and 1.89 times higher than associate students. The chance for women to develop neck pain was 1.83 against men. The odds ratio of Internet addicted students to develop neck pain compared to non-addicted students was 2.45 .

Table 3: Compare the importance of each independent variables on the response variable using the ROC curve

\begin{tabular}{cccccc}
\hline variable & $\mathbf{N}$ & ROC Area & 95\% Cl (Lower-Upper) & chi2 & sig \\
\hline age & 665 & 0.51 & $0.47-0.56$ & 7.90 & 0.048 \\
gender & 665 & 0.54 & $0.50-0.58$ & & \\
education & 665 & 0.52 & $0.48-0.56$ & & \\
addiction & 665 & 0.58 & $0.54-0.62$ & & \\
\hline
\end{tabular}

The effect of each independent variable on neck disorder with the ROC curve analysis showed significant differences $(p=0.048)$. The most significant variables were internet addiction, gender, level of education and age, respectively (Table 3 ).

Fig 1: surface area below the curve for each variable

Figure 1 shows the area below the curve for each of the variables. The values below the curve indicate the importance of different variables in classifying students with or without neck pain. The values below the curve for each independent variable demonstrated the highest predictive accuracy of the Internet addiction. It can therefore be concluded that Internet addiction has the highest accuracy and thus the 
main priority in predicting neck pain in students. Gender, education and age were then prioritized. Chisquare test was used to compare Internet addiction with other three independent variables and the results are presented in Table 4.

Table 4: Comparing each of independent variables with Internet addiction

\begin{tabular}{cccc}
\hline variable & $\mathbf{N}$ & chi2 & sig \\
\hline gender & 665 & 1.96 & 0.162 \\
Age & 665 & 6.28 & 0.012 \\
Education & 665 & 4.99 & 0.025 \\
\hline
\end{tabular}

Comparison of independent variables with internet addiction-most important-showed that age $(p=0.012)$ and education $(p=0.025)$ differed significantly, while gender $(p=0.162)$ has not. It means that addiction and gender have the same effect. Function 1 was obtained using discriminant analysis to predict the chance of neck pain for students.

$\mathrm{Y}=-\mathbf{3 . 0 8 7}+\mathbf{0 . 3 0}($ Education $)+1.30($ Gender $)-0.02($ Age $)+1.95$ (Addiction)

Function 1: the prediction function of individuals who can be placed in the neck pain group. This function can be used to classify students to a group that could have neck pain.

\section{Discussion}

The purpose of this study was to predict neck pain through addiction to virtual social networks and online games. The results showed that addiction could increase the chance of neck disorder by $245 \%$. Along with the results of this study, Zheng et al. showed that over use of the Internet and its contents could cause pain in the neck[17]. In line with the results of the present study, another survey showed that addiction to virtual social networks can cause discomfort in the students' neck[35]. The study by Swedish students confirms these results as well[36]. The results of the review studies, on the other hand, confirmed this study so that problem Internet gaming can lead to psychosomatic disorders, including neck pain[37, 38]. However, in contrast to the results of this study, the results of some studies indicated that there was no relationship between Internet- related content addiction and neck pain[39, 40]. Maybe the difference between socio- economic status and different cultural factors in communities can be interpreted. In other words, these differences can arise at the train level for people regarding emerging issues such as Internet addiction[41, 42].

Other results showed that the risk of neck disorder in women can be higher. Stock et al. studied students from seven different countries and confirmed the results of this study that women are more likely to develop musculoskeletal disorders in the neck[43]. The results of this study were approved for both students and the general population in longitudinal studyies[44-46]. In line with the results of this study, 
Dianat et al. highlighted the difference between male and female students in the report of neck pain[47]. Other studies have also shown that female gender is a risk factor for neck pain[48]. In explaining the impact of gender, despite the results of some studies[49], it can certainly be concluded that female gender has been considered to be a risk factor for neck pain. This is because of differences in women's and men's musculoskeletal systems. Readiness to report or seek medical care for pain or discomfort can be another factor.

Students with higher education were more likely to have neck disorder in this study. Contrary to the results of this study, some studies showed that the level of education has no significant effect on the incidence of musculoskeletal disorders in the neck and shoulders[50, 51]. In a study in Finland, it was found that the risk of pain in the neck region was reduced with increasing levels of education[52]. Perhaps the reason for this difference is the difference in the studied population or the amount of time a student uses the internet-related content. In line with the results of this study, Strine et al. studied 29,828 American adults and reported that neck pain was higher in the subjects with higher education[53]. Diepenmatt et al. also showed that people with higher education are more likely to experience pain in the neck and shoulder[54]. In general, few studies have confirmed that an increase in education can be a risk factor for incidence of neck disorder. This could perhaps be attributed to the time spent on portable computers and touchscreen telephones in higher educated students accessing online content such as research - based activities. The results of multiple logistic regression showed that the students, age did not significantly affect the neck disorder. Other studies in students and workforces also reported results similar to the present study [5557]. In contrast to these results, a recent study showed that an increase in age increases the possibility of developing musculoskeletal disorders in the students' neck[58]. In general, increase in age has always been recognized as a significant risk factor for musculoskeletal disorders in previous studies[59]. This contradiction in results can be attributed to the narrow age range in this study.

Other results showed that addiction to Internet-related content (including addiction to online games and virtual social networks), gender and education are the most important predictors of neck disorder.

Considering the novelty of this study, the results indicated that the ROC can be used to prioritize the effects of different predictors. In this study, the addiction to Internet-related content, gender, and education level in the prediction of neck pain was prioritized respectively. To the best of our knowledge, no previous study prioritizes the predictors of neck pain neither in students nor in the general population. However, it can be concluded from previous studies that the effect size or odds ratio of different variables in the prediction of neck pain is not the same. In a 1-year longitudinal study Leclerc et al. showed that psychological distress and psychosomatic problems had a higher odds ratio than gender for occurrence of neck pain in the next one year[60]. Carroll et al. mentioned that psychosocial factors have a higher predictive power than other factors (individual, occupational, etc.) for neck pain[61]. Despite the differences between the odds ratio, its significance cannot be clearly recognized. Hence, Using ROC regression to prioritize variables is recommended. This study, likewise other cross-sectional ones, cannot determine causal relationship because of not having time dimension. It is suggested that the efficacy of ROC model being tested in longitudinal studies. 


\section{Conclusion}

According to the results, the ability to predict neck pain from addiction to various internet-related content was approved. Due to the relatively high prevalence of this addiction in students, there is a necessity to plan and perform appropriate interventions based on importance of predictors to reduce adverse effects, such as neck pain.

\section{Abbreviation}

ROC: Receiver operating characteristic

\section{Declarations}

Ethics approval and consent to participate

All the scientific and executive stages of this study have been approved by the Ethics Committee of Hamadan University of Medical Sciences (registry number: UMSHA.REC.1397.314). Participating in this study is entirely voluntary.

Consent for publication

Not applicable

Availability of data and material

The datasets used and/or analyzed during the current study are available from the corresponding author on reasonable request.

Competing interests

The authors declare that they have no competing interests

\section{Funding}

Funding for this study was provided by The Vice-Chancellor of Research and Technology of Hamadan university of Medical sciences Grant 9705092792 . This founder had no role in the study design, collection, analysis or interpretation of the data, writing the manuscript, or the decision to submit the paper for publication.

\section{Authors' contributions}

First, second and correspond authors designed the study and wrote the protocol. Third Author conducted literature searches and managing data gathering stage by M. R and K. B. ME. G conducted the statistical analysis. Corresponding Author wrote the first draft of the manuscript and all authors contributed to and have approved the final manuscript.

\section{Acknowledgements}

We appreciate help of Saeedeh Mosaferchi - MSc of ergonomics - for her review of the manuscript. Authors herby thankful of students for their contribution in this study. 


\section{References}

1. Hunt $\mathrm{J}$, Eisenberg D: Mental health problems and help-seeking behavior among college students. Journal of Adolescent Health 2010, 46(1):3-10.

2. School enrollment: social and economic characteristics of students [http://www.census.gov/population/www/socdemo/school/cps2005.html.]

3. Afrasiabi H, Khoobyari F: Student identity and its related factors among students in Yazd Universities. Quarterly Journal of Research and Planning in Higher Education 2016, 21(4):1-19.

4. Blanco C, Okuda M, Wright C, Hasin DS, Grant BF, Liu S-M, Olfson M: Mental health of college students and their non-college-attending peers: results from the national epidemiologic study on alcohol and related conditions. Archives of general psychiatry 2008, 65(12):1429-1437.

5. Ghartappeh A, Talepasand S, Abolfathi M, Solhi M, Gharatappeh S: Relationship Between Personal And Social Adjustment With Locus of Control and Gender in Intelligent High School Student. Iranian Journal of Health Education and Health Promotion 2015, 3(2):159-166.

6. Eisenberg D, Golberstein E, Gollust SE: Help-seeking and access to mental health care in a university student population. Medical care 2007:594-601.

7. Kuss DJ, Griffiths MD, Binder JF: Internet addiction in students: Prevalence and risk factors. Computers in Human Behavior 2013, 29(3):959-966.

8. $\mathrm{Ng} \mathrm{BD}$, Wiemer-Hastings P: Addiction to the internet and online gaming. Cyberpsychology \& behavior 2005, 8(2):110-113.

9. Poli R, Agrimi E: Internet addiction disorder: prevalence in an Italian student population. Nordic journal of psychiatry 2012, 66(1):55-59.

10. Ghamari F, Mohammadbeigi A, Mohammadsalehi N, Hashiani AA: Internet addiction and modeling its risk factors in medical students, Iran. Indian journal of psychological medicine 2011, 33(2):158.

11. Niemz K, Griffiths M, Banyard P: Prevalence of pathological Internet use among university students and correlations with self-esteem, the General Health Questionnaire (GHQ), and disinhibition. Cyberpsychology \& behavior 2005, 8(6):562-570.

12. Young KS: Caught in the net: How to recognize the signs of internet addiction-and a winning strategy for recovery: John Wiley \& Sons; 1998.

13. Kuss DJ, Griffiths MD: Internet gaming addiction: A systematic review of empirical research. International Journal of Mental Health and Addiction 2012, 10(2):278-296.

14. Kuss DJ, Griffiths MD: Online Social Networking and Addiction-A Review of the Psychological Literature. International Journal of Environmental Research and Public Health 2011, 8(9):3528.

15. Kandell JJ: Internet addiction on campus: The vulnerability of college students. Cyberpsychology \& behavior 1998, 1(1):11-17.

16. Byun S, Ruffini C, Mills JE, Douglas AC, Niang M, Stepchenkova S, Lee SK, Loutfi J, Lee J-K, Atallah M: Internet addiction: Metasynthesis of 1996-2006 quantitative research. CyberPsychology \& Behavior 2009, 12(2):203-207. 
17. Zheng Y, Wei D, Li J, Zhu T, Ning H: Internet Use and Its Impact on Individual Physical Health. IEEE Access 2016, 4:5135-5142.

18. Andreassen CS: Online social network site addiction: A comprehensive review. Current Addiction Reports 2015, 2(2):175-184.

19. Al-Dubai SAR, Ganasegeran K, Al-Shagga MAM, Yadav H, Arokiasamy JT: Adverse Health Effects and Unhealthy Behaviors among Medical Students Using Facebook. The Scientific World Journal 2013, 2013:5.

20. Park S-Y, Lim W-T, Kim Y-J, Lee S-W, Yi C-H: The relationship between addiction to online games and carpal tunnel syndrome in college students. Physical Therapy Korea 2009, 16(1):61-69.

21. Aghahi RH, Darabi R, Hashemipour MA: Neck, back, and shoulder pains and ergonomic factors among dental students. Journal of education and health promotion 2018, 7.

22. Kanchanomai S, Janwantanakul P, Pensri P, Jiamjarasrangsi W: Risk factors for the onset and persistence of neck pain in undergraduate students: 1-year prospective cohort study. BMC Public Health 2011, 11(1):566.

23. Hayes M, Smith D, Cockrell D: Prevalence and correlates of musculoskeletal disorders among Australian dental hygiene students. International Journal of Dental Hygiene 2009, 7(3):176-181.

24. Nordander C, Hansson G-Å, Ohlsson K, Arvidsson I, Balogh I, Strömberg U, Rittner R, Skerfving S: Exposure-response relationships for work-related neck and shoulder musculoskeletal disordersAnalyses of pooled uniform data sets. Applied ergonomics 2016, 55:70-84.

25. Zakerian SA, Nedjat S, Mosaferchi S, Ahsani H, Dehghani F, Sepidarkish M, Soufiani AM: Neck disorder influenced by occupational reward type: Results from effort-reward imbalance model based on IPWS. In: Congress of the International Ergonomics Association: 2018: Springer; 2018: 316-325.

26. Piranveyseh P, Motamedzade M, Osatuke K, Mohammadfam I, Moghimbeigi A, Soltanzadeh A, Mohammadi $\mathrm{H}$ : Association between psychosocial, organizational and personal factors and prevalence of musculoskeletal disorders in office workers. International Journal of Occupational Safety and Ergonomics 2016, 22(2):267-273.

27. Critselis E, Janikian M, Paleomilitou N, Oikonomou D, Kassinopoulos M, Kormas G, Tsitsika A: Predictive factors and psychosocial effects of Internet addictive behaviors in Cypriot adolescents. International journal of adolescent medicine and health 2014, 26(3):369-375.

28. Müller KW, Dreier M, Beutel ME, Duven E, Giralt S, Wölfling K: A hidden type of internet addiction? Intense and addictive use of social networking sites in adolescents. Computers in Human Behavior 2016, 55:172-177.

29. Vilca LW, Vallejos M: Construction of the risk of addiction to social networks scale (Cr. ARS). Computers in Human Behavior 2015, 48:190-198.

30. Ghaempanah: The Study of the Relationship between Addiction to Social Networks and Online Games with Academic Performance in Hamadan University of Medical Sciences Students. Hamadan university of medical sciences; 2017. 
31. Demetrovics Z, Urbán R, Nagygyörgy K, Farkas J, Griffiths MD, Pápay O, Kökönyei G, Felvinczi K, Oláh A: The development of the problematic online gaming questionnaire (POGQ). PloS one 2012, 7(5):e36417.

32. Kuss DJ: Internet gaming addiction: current perspectives. Psychology research and behavior management 2013, 6:125.

33. AMINI MS, NAZARI AM, MORADI A, FARZAD V: YOUTH ONLINE GAMING ADDICTION: THE ROLE OF SELF ESTEEM, ANXIETY AND DEPRESSION. 2014.

34. Kuorinka I, Jonsson B, Kilbom A, Vinterberg H, Biering-Sørensen F, Andersson G, Jørgensen K: Standardised Nordic questionnaires for the analysis of musculoskeletal symptoms. Applied ergonomics 1987, 18(3):233-237.

35. Zheng X, Lee MK: Excessive use of mobile social networking sites: Negative consequences on individuals. Computers in Human Behavior 2016, 65:65-76.

36. Hellström C, Nilsson KW, Leppert J, Åslund C: Effects of adolescent online gaming time and motives on depressive, musculoskeletal, and psychosomatic symptoms. Upsala journal of medical sciences 2015, 120(4):263-275.

37. Yau YH, Crowley MJ, Mayes LC, Potenza MN: Are Internet use and video-game-playing addictive behaviors? Biological, clinical and public health implications for youths and adults. Minerva psichiatrica 2012, 53(3):153.

38. Paulus FW, Ohmann S, von Gontard A, Popow C: Internet gaming disorder in children and adolescents: a systematic review. Developmental Medicine \& Child Neurology 2018.

39. Gür K, Yurt S, Bulduk S, Atagöz S: Internet addiction and physical and psychosocial behavior problems among rural secondary school students. Nursing \& health sciences 2015, 17(3):331-338.

40. Masthi NR, Pruthvi S, Mallekavu P: A Comparative Study On Social Media Addiction Between Public And Private High School Students Of Urban Bengaluru, India. ASEAN Journal of Psychiatry 2017, 18(2):72-81.

41. Griffiths MD: Social networking addiction: Emerging themes and issues. Journal of Addiction Research \& Therapy 2013, 4(5).

42. Avgerou C, Madon S: Information society and the digital divide problem in developing countries. In: Perspectives and policies on ICT in society. edn.: Springer; 2005: 205-217.

43. Stock C, Mikolajczyk RT, Bilir N, Petkeviciene J, Naydenova V, Dudziak U, Marin-Fernandez B, El Ansari W: Gender differences in students' health complaints: a survey in seven countries. Journal of Public Health 2008, 16(5):353-360.

44. Hanvold TN, Veiersted KB, Wærsted M: A prospective study of neck, shoulder, and upper back pain among technical school students entering working life. Journal of Adolescent Health 2010, 46(5):488-494.

45. Croft PR, Lewis M, Papageorgiou AC, Thomas E, Jayson MI, Macfarlane GJ, Silman AJ: Risk factors for neck pain: a longitudinal study in the general population. Pain 2001, 93(3):317-325. 
46. Hallman DM, Rasmussen CDN, Jørgensen MB, Holtermann A: Time course of neck-shoulder pain among workers: A longitudinal latent class growth analysis. Scandinavian journal of work, environment \& health 2018, 44(1):47-57.

47. Dianat I, Sorkhi N, Pourhossein A, Alipour A, Asghari-Jafarabadi M: Neck, shoulder and low back pain in secondary schoolchildren in relation to schoolbag carriage: Should the recommended weight limits be gender-specific? Applied ergonomics 2014, 45(3):437-442.

48. Ehsani F, Mohseni-Bandpei MA, Fernández-De-Las-Peñas C, Javanshir K: Neck pain in Iranian school teachers: Prevalence and risk factors. Journal of bodywork and movement therapies 2018, 22(1):6468.

49. Östergren P-O, Hanson BS, Balogh I, Ektor-Andersen J, Isacsson A, Örbaek P, Winkel J, Isacsson S-O: Incidence of shoulder and neck pain in a working population: effect modification between mechanical and psychosocial exposures at work? Results from a one year follow up of the Malmö shoulder and neck study cohort. Journal of Epidemiology \& Community Health 2005, 59(9):721-728.

50. Picavet H, Schouten J: Musculoskeletal pain in the Netherlands: prevalences, consequences and risk groups, the DMC3-study. Pain 2003, 102(1-2):167-178.

51. Alexopoulos EC, Stathi I-C, Charizani F: Prevalence of musculoskeletal disorders in dentists. BMC musculoskeletal disorders 2004, 5(1):16.

52. Mäkela M, Heliövaara M, Sievers K, Impivaara O, Knekt P, Aromaa A: Prevalence, determinants, and consequences of chronic neck pain in Finland. American journal of epidemiology 1991 , 134(11):1356-1367.

53. Strine TW, Hootman JM: US national prevalence and correlates of low back and neck pain among adults. Arthritis Care \& Research 2007, 57(4):656-665.

54. Diepenmaat A, Van der Wal M, De Vet H, Hirasing R: Neck/shoulder, low back, and arm pain in relation to computer use, physical activity, stress, and depression among Dutch adolescents. Pediatrics 2006, 117(2):412-416.

55. Kurşun Ş, Evirgen S, Akbulut N, Oztas B, Vaizoglu SA: Work characteristics and musculoskeletal disorders among postgraduate dental students: A pilot study. Journal of Musculoskeletal Pain 2014, 22(1):62-67.

56. Lövgren M, Gustavsson P, Melin B, Rudman A: Neck/shoulder and back pain in new graduate nurses: A growth mixture modeling analysis. International journal of nursing studies 2014, 51(4):625-639.

57. Pelissier C, Fontana L, Fort E, Agard JP, Couprie F, Delaygue B, Glerant V, Perrier C, Sellier B, Vohito M: Occupational risk factors for upper-limb and neck musculoskeletal disorder among health-care staff in nursing homes for the elderly in France. Industrial health 2014, 52(4):334-346.

58. Namwongsa S, Puntumetakul R, Neubert MS, Boucaut R: Factors associated with neck disorders among university student smartphone users. Work 2018(Preprint):1-12.

59. McLean SM, May S, Klaber-Moffett J, Sharp DM, Gardiner E: Risk factors for the onset of non-specific neck pain: a systematic review. Journal of Epidemiology \& Community Health 2010, 64(7):565-572. 
60. Leclerc A, Niedhammer I, Landre M-F, Ozguler A, Etore P, Pietri-Taleb F: One-year predictive factors for various aspects of neck disorders. Spine 1999, 24(14):1455.

61. Carroll LJ, Hogg-Johnson S, van der Velde G, Haldeman S, Holm LW, Carragee EJ, Hurwitz EL, Côté P, Nordin M, Peloso PM: Course and prognostic factors for neck pain in the general population: results of the Bone and Joint Decade 2000-2010 Task Force on Neck Pain and Its Associated Disorders. Journal of manipulative and physiological therapeutics 2009, 32(2):S87-S96.

\section{Figures}

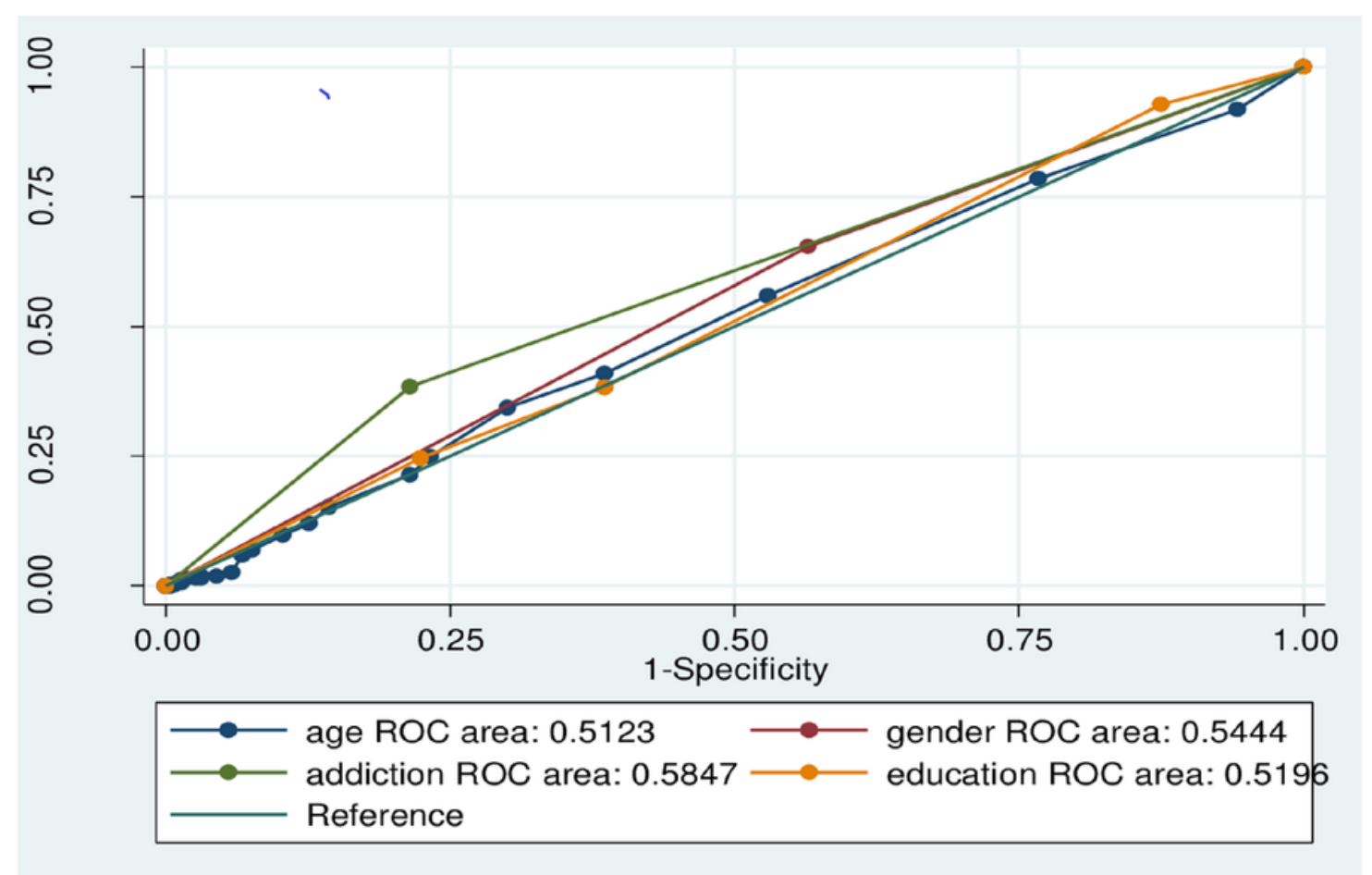

Fig 1: surface area below the curve for each variable

\section{Figure 1}

surface area below the curve for each variable 